\title{
Anxiety in Chinese Language Learning: Relationship to Motivation, Attitude, and Achievement
}

Qi Wang ${ }^{1}$, Fengning Du ${ }^{2}$

${ }^{1}$ Middlebury Institute of International Studies, Monterey

${ }^{2}$ Chinese Language Teachers Association of California, Monterey

\section{United States}

Correspondence: Qi Wang. Department of Translation, Interpretation, and Language Education, 460 Pierce St, Monterey, CA 93940, United States. E-mail: qiw@middlebury.edu

(C) Universidad de Almería and Ilustre Colegio Oficial de la Psicología de Andalucía Oriental (Spain) 


\begin{abstract}
Introduction. In the past decades, studies have been conducted to explore the role of anxiety in the learning of Western languages such as English, French, and Spanish. However, when it comes to the predictive relationship between anxiety, motivation, attitude, and Chinese achievement, the findings are inconclusive. This study aims to test a model of relationship among anxiety, motivation, integrativeness, attitude, and Chinese achievement.
\end{abstract}

Method. Structural equation modeling was conducted on a sample of 223 international students enrolled in Chinese courses at a university in China. A total of 14 variables indicating anxiety, motivation, integrativeness, attitudes toward the learning situation, and Chinese achievement were included in the analysis.

Results. Results indicated that students of Chinese experienced a moderate level of anxiety in Chinese learning. Anxiety had a direct and negative effect on Chinese achievement. Positive attitudes toward the learning situation had a positive effect on students' motivation to learn. However, in the current sample, integrativeness and motivation are not separable, instead they formed a general motivation construct that predicted students' course grades but not proficiency test grades.

Discussion and Conclusion. The results of structural equational modeling generally confirmed Gardner's socio-educational model of second-language acquisition. Consistent with previous literature on second language anxiety, this study found a small negative effect of anxiety on achievement and a strong positive effect of attitudes toward the learning situation on motivation. In addition, motivation predicted Chinese achievement when it is measured by course grade. It is therefore appropriate to conclude that anxiety and motivation both contributed to the prediction of Chinese achievement when it was measured by course grade.

Keywords: Anxiety, motivation, integrativeness, attitude, language achievement 


\section{Resumen}

Introducción. En las décadas pasadas, los estudios han conducido a explorar el rol de la ansiedad en el aprendizaje de las lenguas occidentales como el ingles, francés y español. Sin embargo, cuando se trata de la relación predictiva entre la ansiedad, variables motivacionales, y el éxito del chino, los hallazgos son inconclusos. Este estudio tiene como objetivo probar un modelo de relación entre la ansiedad, motivación, integrabilidad, actitud, y el éxito del Chino.

Método. El modelo de la ecuación estructural se condujo en una muestra de 223 estudiantes internacionales inscritos en los cursos de chino en una universidad en China. Un total de 14 variables indicando ansiedad, motivación, integrabilidad, actitud hacia la situación de aprendizaje, y el éxito del chino se incluyeron en el análisis.

Resultados. Los resultados indicaron que los estudiantes de chino experimentaban un nivel moderado de ansiedad en el aprendizaje de chino. La ansiedad tiene un efecto directo y negativo en el éxito del chino. Las actitudes positivas hacia la situación de aprendizaje tienen un efecto positivo en la motivación de los estudiantes para aprender. En la muestra actual, la integrabilidad y motivación no eran separables. Se encontró que la motivación podía predecir las notas de un curso de los estudiantes pero no sus notas del examen de aptitud.

Discusión y Conclusión. Los resultados del modelo de la ecuación estructural generalmente confirman el modelo socio-educacional de Gardner de la adquisición de una segunda lengua. Consistente con literatura previa sobre la ansiedad de lenguaje, este estudio encontró un pequeño efecto negativo en la ansiedad del lenguaje sobre el éxito y un fuerte efecto positivo de actitudes hacia la situación de aprendizaje sobre la motivación. Además, la motivación predijo el éxito del chino cuando se mide por la nota del curso. Es, por lo tanto, apropiado concluir que la ansiedad y motivación ambas directamente influenciaron el éxito del chino cuando se midió por nota de curso.

Palabras clave: Ansiedad, motivación, integrabilidad, actitud, éxito del lenguaje. 


\section{Introduction}

Language learning may be a stressful experience for many learners (Horwitz, Horwitz, \& Cope, 1986; Kim, 2000; Luo, 2018; Trang, Baldauf Jr., \& Moni, 2013). It is common to observe students in language classrooms who experience "freezing up" when answering questions, find it very difficult to concentrate in listening and reading tasks, or claim they knew the correct answer but put down the wrong one due to nervousness. These behaviors in language learning are considered manifestations of second language anxiety, which is defined as "the feeling of tension and apprehension specifically associated with second-language context" (MacIntyre \& Gardner, 1994, p. 284). To date, research on second language anxiety has reported about one third to two thirds of learners in second or foreign language classrooms experienced anxiety (Kim, 2000; Shao, Yu, \& Ji, 2013; Trang, et al., 2013) ranging from moderate to high based on various anxiety scales (Le, 2004; Luo, 2018; Rastegar \& Karami, 2015; Subekti, 2018; Yu \& Watkins, 2008; Zhao \& Whitchurch, 2011).

In the past decades, studies have been conducted to explore the role of anxiety in the learning of Western languages such as English, French, and Spanish. These studies found that anxiety was a significant predictor of language achievement even when other major affective variables, such as motivation, attitude and self-efficacy, were controlled (Gardner \& Bernaus, 2010; Shih, 2019; Woodrow, 2011). However, when it comes to the predictive relationship between anxiety and Chinese achievement, the research is scarce, and the findings are inconclusive. Yu and Watkins (2008) is the first and only study that investigated anxiety and Chinese achievement of international students in China. This study revealed a small negative correlation between anxiety and Chinese proficiency $(\mathrm{r}=-.27)$, but neither anxiety nor motivation was found to predict students' Chinese proficiency, which is inconsistent with previous research on second language anxiety.

This discrepancy in findings may be attibuted to the different educational contexts. Study abroad programs differ from domestic programs in significant ways. Students in study abroad programs come from more diverse linguistic and cultural backgrounds; the immediate contact with the target language may be either more motivating or more anxiety-provoking for them; Further, students who are familiar with the academic culture may be less anxious than those who aren't. There is a dearth of empirical studies undertaken to illuminate the role of anxiety in study abroad programs, espeically those with a diverse student popultion. With a 
student sample from twenty eight countries, this study significantly advances current knowledge base. Grounded in the socio-educational model of second language acquisition (Gardner, 1985, 2006), this study aims to test a model of relationship among anxiety, motivation, integrativeness, attitude, and Chinese achievement. In the present study, multiple measures of anxiety, achievement, and affective variables were adopted to provide stronger support to the research findings.

\section{Anxiety}

Second Language anxiety has garnered the attention of the research community since the 1970s. Due to inconsistency in the definition and measurement of anxiety, mixed results have been reported regarding the effects of anxiety on language learning and achievement (Scovel, 1978). In the late 1980s, researchers (Horwitz et al., 1986; MacIntyre \& Gardner, 1989) differentiated second language anxiety from trait anxiety and state anxiety (Spielberger, 1976). Second language anxiety was conceptualized as a situation-specific anxiety, embedded in the foreign- or second-language learning context. Since then, research using anxiety measures specific to the language-learning context has discovered adverse effects of anxiety on language learning and achievement.

A number of studies have reported a negative relationship between second language anxiety and achievement measures across languages and social-educational contexts (Awan, Azher, Anwar, \& Naz, 2010; Gardner, 2006, 2012; Salehi \& Marefat, 2014; Zhang, 2019; Zhao \& Whitchurch, 2011). Anxiety was found to reduce students' performance at the input, processing, and output stages of language learning (MacIntyre \& Gardner, 1994; Pérez Castillejo, 2019), and the presence of anxiety may increase the cognitive load of the learners so that fewer resources can be allocated to comprehension (Chen \& Chang, 2009). Behaviorally, people with high second language anxiety tend to avoid activities that involve the second or foreign language. For example, Bekleyen (2009) found that students with high English listening anxiety would avoid watching English TV programs, talking to native speakers, or participating in classroom activities that require listening.

\section{Motivaton}

The research on second language motivation can be traced back to over forty years. Since then, many theories of L2 motivation have been proposed, advocating different perspectives concerning the nature and operationalization of motivation. Gardner (1985, 2006)'s so- 
cio-educational model of second language acquisition is one of the leading theories that laid the foundation for many studies in second language motivation. The major assumption of this theory is that language learners' motivation is shaped by the social and educational contexts they are situated in (Masgoret and Gardner, 2003, Gardner, 2006). The latest emerging theory on second language motivation is concerned with learners' self-perceptions (Dörnyei 2005, 2009). The learners' desired self-images and their actual learning experience could produce the motivation to learn a language. Despite the different conceptualizations of motivation in second language learning, it is generally accepted that motivation plays a critical role in second language acquisition (Cocca \& Cocca, 2019; Dörnyei, 2005; Masgoret \& Gardner, 2003; Shih \& Change, 2018).

\section{Integrativenss and attitude}

Integrativeness is the learners' willingness to incorporate the linguistic and behavioral patterns of the cultures associated with the target langauge (Gardner, 2006). Integrativness has been found to be closely related to language achievement. For instance, Hernández (2008)'s study on Spanish learners found that among various reasons to learn the language (i.e. integrative orientation, instrumental orientation, and foreign language requirement), students' integrative orientation was the only predictor of their speaking performance after controlling for students' GPA and years learning Spanish. Similarly, Sultan and Hussain (2010)'s study, which examined the integrative and instrumental orientation for EFL learners, found that overall the students' achievement was positively associated with their integrative orientation but not with their instrumental orientation.

Another attitudinal aspect concerns students' attitudes toward the learning environment. It is believed that language teachers' behaviors and characteristics could have an effect on students' achievement ( Nouri, 2015; Swanson, 2013; Talebinejad \& Akhgar, 2015). Likewise, students' perception of the teacher could also have an effect on their achievement. Students who have more positive attitudes toward their teachers may have higher course grades (Vahdany, Sabouri, \& Ghafarnian, 2015). Those who perceive stronger teacher control in class tend to have lower language achievement than their counterparts who perceive less teacher control (Kiany and Shayestefar, 2011). 
Towards a model of anxiety, motivation, integrativeness, attitude, and achievement

A significant body of studies have been conducted to explore the role of anxiety and other affective variables in predicting students' second language achievement. Motivation and anxiety were found to be significant predictors of students' English course grades (Gardner \& Bernaus, 2010). Similar findings were observed in the learning of Spanish, German, and French. For instance, Sparks, Patton, Ganschow, \& Humbach (2009) found that motivation and anxiety added significantly to the prediction of students' second language (i.e. Spanish, German, French) proficiency even after language aptitude was considered.

When it comes to the predictive relationship between anxiety and Chinese achievement, however, research findings have been inconclusive. Zhao and Whitchurch (2011), in their study of college learners studying Chinese in the US, found a negative correlation between second language anxiety and students' final course grades, suggesting that students with higher anxiety in Chinese class tend to receive lower final grades. Yu and Watkins (2008) investigated the relative importance of anxiety and affective variables in predicting Chinese achievement. They found that among a number of affective and background variables (i.e. motivation, anxiety, integrativeness, instrumental orientation, gender), integrativeness and gender were the only predictors of Chinese language proficiency. This finding is inconsistent with previous research that revealed a significant contribution of anxiety and motivation to the prediction of language achievement.

Multiple factors may have contributed to the inconsistent findings on the role of anxiety in predicting Chinese achievement. Given that Yu and Watkins (2008) examined international students studying Chinese in China, a group that may be fundamentally different in goals, motivation, and attitudes in learning, it is possible that the way by which anxiety functions is different in international Chinese programs and domestic language programs. Another possibility lies in the measurement of language achievement. Yu and Watkins (2008) used one achievement measure, which is teacher's ratings of students' language proficiency. Multiple measures of language achievement are needed to provide stronger support to the research findings.

\section{Objectives and Hypotheses}

The purpose of the present study therefore is to extend previous research on second language anxiety by testing a model of relationship between anxiety, motivational variables, 
and Chinese language achievement. Gardner's $(1985,2006)$ socio-educational model provides a theoretical framework for this study. Gardner (1985) proposed that the social milieu in which language learning occurs could influence the language learning process and the learning outcomes. The social influence is reflected by learners' integrativeness; the educational influence is reflected by the learners' attitudes toward the learning situation which refers to the educational contexts in which the learning occurs. The learning situation can be as broad as government policies or as specific as the teacher, the course material, and instruction. In this study, the learning situation is measured by students' evaluation of the teacher variables and the quality of the language course. Gardner (2006) further postulated that integrativeness and attitudes toward the learning environment directly influence individual's motivation to learn a language. Motivation and anxiety then directly influence the language achievement.

Grounded in Gardner's theory, this study aims to explore the anxiety profile of one particular group learners of Chinese and to test whether there is a relationship between the following constructs: anxiety, motivation, integrativeness, attitudes toward the learning situation, and language achievement. Based on empirical studies and theoretical considerations, this study tested the following hypotheses:

1. Learners of Chinese experience anxiety in their language learning.

2. Anxiety, motivation, integrativeness, and attitudes toward the learning situation are constructs that are independent from each other.

3. Anxiety negatively predicts Chinese achievement. Motivation positively predicts Chinese achievement. Integrativenss and attitudes toward the learning situation directly predict motivation and indirectly predict Chinese achievement through motivation.

\section{Method}

\section{Participants}

The participants were students from a university in Southwestern China. The location of the study was the International College of the university, which offered Chinese language courses to both degree-seeking students as part of their degree requirements and to nondegree students as part of their language-training curriculum. All participants were non-native speakers of Chinese. A total of 223 students participated in the study. They came from 28 countries with an average age of 21 . The participant demographics are presented in Table 1. 
Table 1. Participant Demographics $(N=223)$

\begin{tabular}{lcc}
\hline & $\begin{array}{r}\text { Number of } \\
\text { participants }\end{array}$ & $\begin{array}{c}\text { Percentage of } \\
\text { participants }\end{array}$ \\
\hline Gender & 78 & 35 \\
Male & 145 & 65 \\
Female & & \\
Major & 109 & 49 \\
$\quad$ Chinese Language and Literature & 60 & 27 \\
International Education & 21 & 9 \\
Business Management & 33 & 15 \\
Language Training & & \\
World Region & 187 & 84 \\
Asia & 20 & 9 \\
Africa & 9 & 4 \\
Europe & 5 & 2 \\
North America & 2 & 1 \\
South America & & \\
Course level & 90 & 40 \\
Elementary & 109 & 49 \\
Intermediate & 24 & 11 \\
Advanced & &
\end{tabular}

\section{Instruments}

\section{Anxiety and motivational variables}

Students' second language anxiety was measured by the Chinese Language Learning Anxiety Scale (Luo, 2014). This scale was chosen because it targets Chinese language learning anxiety and measures anxiety in all four skills (i.e. listening, speaking, reading, and writing). This 5-point Likert scale consisted of three subscales: speaking anxiety, listening anxiety, and reading and writing anxiety. A higher score indicates higher anxiety in language learning.

Motivation, integrativeness, and attitudes toward the learning situation were measured by a scale adapted from the international Attitude and Motivation Test Battery by Gardner (2010). Because the international AMTB was created for teenage learners of English as a foreign language, adaptations are needed to reflect the Chinese learning context in the present study. The adaptation includes changing the target language from "English" to "Chinese", changing "English speaking countries" to "Chinese speaking countries and regions", and changing "my high school program" to "my college program". In addition, given that the current sample of students took multiple Chinese courses with different teachers, they were asked to evaluate "this course" instead of "Chinese course" and "teacher of this course" rather 
than "Chinese teacher" to reflect their attitudes and motivation in the Comprehensive Chinese course chosen for this study. All these minor modifications relate to contextual information, thus preserving the original meaning of the survey ítems as well as the content validity of AMTB.

The motivation scale includes three subscales: motivational intensity, desire to learn Chinese, and attitudes toward learning Chinese. An example of the survey items is "If it were up to me, I would spend all my time learning Chinese". The integrativeness scale includes integrative orientation, attitudes toward Chinese speakers, and interest in foreign languages. A sample item is "Studying Chinese is important because it will enable me to better understand and appreciate the Chinese way of life". Attitudes toward the learning was measured by two subscales: evaluation of the course and evaluation of the teacher. Students were asked to rate statements such as "I look forward to the time I spend in this class" and "My Chinese teacher has a dynamic and interesting teaching style". All the items were graded on a scale from 1 to 7. A higher score represented higher motivation, higher integrativeness, or a more positive attitudes toward the learning environment. Table 2 shows the reliability estimates of the above-mentioned scales.

Table 2. Number of Test Items and Cronbach's Alpha for All Scales

\begin{tabular}{llcc}
\hline \multicolumn{1}{c}{ Scales } & \multicolumn{1}{c}{ Subscales } & Number of items & $\boldsymbol{\alpha}$ \\
\hline Chinese Language Learn- & Speaking anxiety & 4 & .63 \\
ing Anxiety Scale & Listening anxiety & 4 & .63 \\
(Luo, 2014) & Reading and writing anxiety & 8 & .65 \\
& Overall & 16 & .79 \\
Attitude and Motivation & Motivational intensity & 10 & .73 \\
Test battery, adapted from & Desire to learn Chinese & 10 & .76 \\
Gardner (2010) & Attitudes toward learning Chinese & 10 & .81 \\
& Integrative orientation & 4 & .83 \\
& Attitudes toward Chinese speakers & 8 & .79 \\
& Interest in foreign languages & 10 & .81 \\
& Evaluation of the teacher & 10 & .85 \\
& Evaluation of the course & 10 & .88 \\
& Overall & 72 & .94 \\
\hline
\end{tabular}




\section{Outcome variables}

Students' Chinese language achievement was measured by an HSK listening test, an HSK reading test, and students' final course grade in the Comprehensive Chinese course. The HSK test is a standardized Chinese proficiency test developed by the Office of Chinese Language Council International under the jurisdiction of Ministry of Education of People's Republic of China. The test is divided into six levels, from Level I to Level VI. The higher levels correspond to higher language proficiency. The current study used the 2013 HSK tests obtained from the Confucius Institute at the University of Manchester. Because an HSK test is not an adaptive test, students from different proficiency levels had to take different tests. Therefore, three tests (i.e., HSK IV, HSK V, and HSK VI) were used for students at the beginning, intermediate, and advanced levels, respectively. The number of items and Cronbach's alpha for each test are shown in Table 3. Because there is a different number of items for each test, mean item score was used as a measure of performance. Furthermore, given that the test selection was based on teachers' recommendations, the test scores were standardized within each class to rule out bias on test selection.

Table 3. Number of Test Items and Cronbach's Alpha for the HSK Tests

\begin{tabular}{rlcc}
\hline \multicolumn{1}{c}{ Test Level } & Test & Number of Items & $\boldsymbol{\alpha}$ \\
\hline HSK Level IV & Listening & 45 & .88 \\
& Reading & 40 & .93 \\
HSK Level V & Listening & 45 & .90 \\
& Reading & 45 & .90 \\
HSK Level VI & Listening & 50 & .84 \\
& Reading & 50 & .82 \\
\hline
\end{tabular}

The final course grade was composed of the students' final exam grades (50\%), attendance $(20 \%)$, homework $(10 \%)$, quizzes $(10 \%)$, and participation $(10 \%)$ in the Comprehensive Chinese course. To make the grades comparable, the final grades were also standardized within each class to control for teachers' influence on grading.

\section{Procedure}

The data collection lasted 4 months. A 98-item survey was compiled, including a Chinese Language Learning Anxiety Scale (Luo, 2014), eight subscales adapted from the in- 
ternational Attitude and Motivation Test Battery (Gardner, 2010), and a background questionnaire. The items on the survey were translated into Chinese by the researcher and back translated by an English teacher at a university in China. Given that students at the elementary level may have difficulty understanding the Chinese survey and that many students came from non-English-speaking countries, the English survey was further translated by certified translators into seven languages: Thai, Russian, Vietnamese, French, Korean, Japanese, and Arabic. These languages were considered the most commonly spoken languages of the participants, according to the information provided by the department official.

Fifteen instructors of the Comprehensive Chinese course were contacted. Individual meetings were scheduled with each instructor, during which the purpose and procedures of the study were discussed. Teachers were invited to review the Chinese survey and the HSK tests. The teachers were asked to comment on the appropriateness and readability of the survey and whether the HSK test was appropriate in difficulty for their class. The Chinese version of the survey was considered appropriate by all the teachers.

The data collection was carried out in three phases. In April, the researcher visited all 18 classes to introduce the study and recruit participants. Those who were willing to participate in the study would complete the written survey after class. To ensure the confidentiality of students' responses, the survey was kept in envelopes and collected by the researcher the following day. In May, the participants took an HSK test that included listening and reading tests. In June, the participants' final course grades in the Comprehensive Chinese courses were collected from the department registry.

\section{Datal Analysis}

Before conducting data analysis, primary analyses were performed to check missing data and the normality of the data distribution. The pattern of missing values was assessed by Little's Missing Completely at Random (MCAR) test. A nonsignificant Little's MCAR test of all 14 variables (11 independent variables and 3 outcome variables), $\chi^{2}(389)=381.43, p$ $=.60$, indicated that the data were missing completely at random (Little, 1988). Because the data were missing completely at random and only a small portion of the data was missing, a single imputation with the expectation maximization algorithm was performed, as it can provide unbiased parameter estimates (Enders, 2001; Scheffer, 2002). After imputing the missing data, the normality of all variables was assessed. According to Kline (2011), a variable is nor- 
mally distributed if its skewness index (i.e., skewness statistic/standard error) is less than three and its kurtosis index (i.e., kurtosis statistic/standard error) is less than 20. Log transformation was applied to eight variables (i.e. integrative orientation, attitudes toward Chinese speakers, interest in foreign languages, desire to learn, attitudes toward learning Chinese, teacher evaluation, course evaluation, and course grade) that had a skewness index above three.

The data analysis consisted of three parts. First, descriptive statistics on anxiety measures (e.g., means, standard deviations, range) were used to illuminate the students' level of anxiety in Chinese learning. Second, correlations between the 14 variables were analyzed using principal component analysis followed by varimax rotation to examine the construct validity of anxiety, motivation, integrativenss, attitudes toward the learning situation, and Chinese achievement. Third, a latent-variable structural equation model was tested to investigate the predictive relationship of anxiety, motivation, integrativenss, attitudes toward the learning situation, and Chinese achievement. Before conducting the structural equation modeling, several assumptions were tested. Kline (2011) noted that one can detect multivariate non-normality by assessing univariate normality. Because all variables were distributed normally after data transformation, the assumption of multivariate normality was met. Furthermore, two collinearity statistics, tolerance and the variance inflation factor (VIF), were examined to determine collinearity among the independent variables. A tolerance value less than .10 and a VIF larger than 10 are deemed problematic (Keith, 2015). This assumption was met because all the variables had tolerance larger than 1 and VIF less than 10. After checking all the assumptions, structural equation modeling was applied to the modified model using LISREL 9.30.

\section{Results}

\section{Descriptive data}

The findings supported the first hypothesis that learners of Chinese experience anxiety in their language learning. Table 4 shows the means, standard deviations, and ranges of the three anxiety measures. The mean speaking anxiety was 10.91 on a scale of 20 , which indicates a moderate level of anxiety in speaking. The mean listening anxiety was 11.36 on a scale of 20, which can be considered moderate. The reading and writing anxiety measure was 21.13 on a scale of 40, suggesting a moderate level of anxiety in reading and writing activities. Overall, the students did not report high anxiety in Chinese language learning, and there 
was no noticeable difference on the anxiety level across language skills (i.e., listening, speaking, reading, and writing).

Table 4. Means, Standard Deviations, Minimum, and Maximum of Anxiety Variables $(N=223)$

\begin{tabular}{lcccc}
\hline \multicolumn{1}{c}{ Variables } & Mean & SD & Minimum & Maximum \\
\hline Speaking Anxiety & 10.91 & 2.99 & 4 & 18 \\
Listening Anxiety & 11.36 & 3.07 & 4 & 19 \\
Reading Writing Anxiety & 21.13 & 4.20 & 8 & 36 \\
Total & 43.40 & 8.04 & 16 & 66 \\
\hline
\end{tabular}

\section{Construct validity}

The second hypothesis concerns the construct validity of the proposed model. The findings partially supported this hypothesis that anxiety, achievement, and attitudes toward the learning situation are independent from each other in predicting Chinese achievement. Motivation and integrativeness, however, were not found to be distinguishable. Table 5 shows the results of the principal component analysis.

Table 5. Results of Principal Component Analysis with Varimax Rotation $(N=223)$

\begin{tabular}{lcccc}
\hline \multicolumn{1}{c}{ Variables } & Achievement & Anxiety & $\begin{array}{c}\text { Attitudes Toward } \\
\text { Learning Situation }\end{array}$ & Motivation \\
\hline Speaking Anxiety & -.17 & .67 & .15 & .09 \\
Listening Anxiety & -.03 & .81 & -.12 & .01 \\
Reading Writing Anxiety & -.08 & .78 & .17 & .08 \\
Integrative Orientation & .08 & .04 & .03 & .78 \\
Attitudes Toward Native & -.05 & -.23 & .30 & .67 \\
Speakers & & & & .74 \\
Interest in Foreign Languages & -.10 & .17 & .06 & -.59 \\
Motivational Intensity & .23 & -.26 & -.36 & .82 \\
Desire to Learn Chinese & .04 & .13 & .21 & .75 \\
Attitudes Toward Learning Chi- & -.02 & .13 & .35 & .28 \\
nese & & & & .31 \\
Teacher Evaluation & -.00 & .08 & .85 & .21 \\
Course Evaluation & -.06 & .09 & .82 & .05 \\
Course Grade & -.77 & .21 & -.12 & .06 \\
HSK Listening & .88 & .00 & -.06 & \\
HSK Reading & .85 & -.12 & -.13 & \\
\hline
\end{tabular}


The principal component analysis with varimax rotation identified four factors with eigenvalues larger than one. The four-factor solution explained $68 \%$ of the total variance. The first factor was defined as achievement because it obtained loadings above .80 from the three measures of Chinese achievement. The second factor was defined as anxiety because the three anxiety measures loaded above .80 on this factor. The third factor was labeled attitudes toward the learning situation as it obtained high loadings from the measures of teacher evaluation and course evaluation. Finally, in contrast to the hypothesized five-factor structure, the three measures of integrativeness and the three measures of motivation all loaded on the same factor, making the integrativenss construct and motivation construct not distinguishable. This is interpreted as indicating that the motivation to learn Chinese in the current student sample is associated with both their attitudes toward learning the language (motivational intensity, desire to learn Chinese, attitudes toward learning Chinese) and attitudes toward the Chinese speaking community (integrative orientation, attitudes toward native speakers, interest in foreign languages). Therefore, the last factor was labeled motivation.

\section{Structural Equation model}

To test the third hypothesis that anxiety and motivation directly influence Chinese achievement and that attitudes toward the learning situation directly influence motivation, a latent-variable structural model was conducted via LISREL. The findings partially supported the third hypothesis, suggesting a small effect of anxiety on Chinese achievement and a large effect of attitudes toward the learning situation on motivation. Motivation had an effect on students' course grade but not on their proficiency test scores.

Given that the previous principal component analysis revealed a four-factor structure in which measures of motivation and integrativeness are not separable, the structural model tested consisted of four constructs: anxiety, motivation, attitudes toward the learning situation, and language achievement (See Figure 1).

The goodness-of-fit of the proposed model was evaluated though multiple fit statistics, including the Comparative Fit Index (CFI), the Root Mean Square Error of Approximation (RMSEA), and the Standardized Root Mean Square Residual (SRMR). Although Chi-square is a commonly reported fit statistics, it is problematic as a measure of the fit of a single model because it is sensitive to sample size (Keith, 2015). A large sample size tends to yield large Chi square that is statistically significant, pointing to a poor model fit. Therefore, alternative 
fit indexes were examined to determine the fit of the proposed model. Specifically, a model is considered to fit the data well when the CFI is not smaller than .95 (Keith, 2015), the RMSEA not larger than .06 (Hu \& Bentler, 1999; Steiger, 2007), and the SRMR not larger than .08 (Keith, 2015).

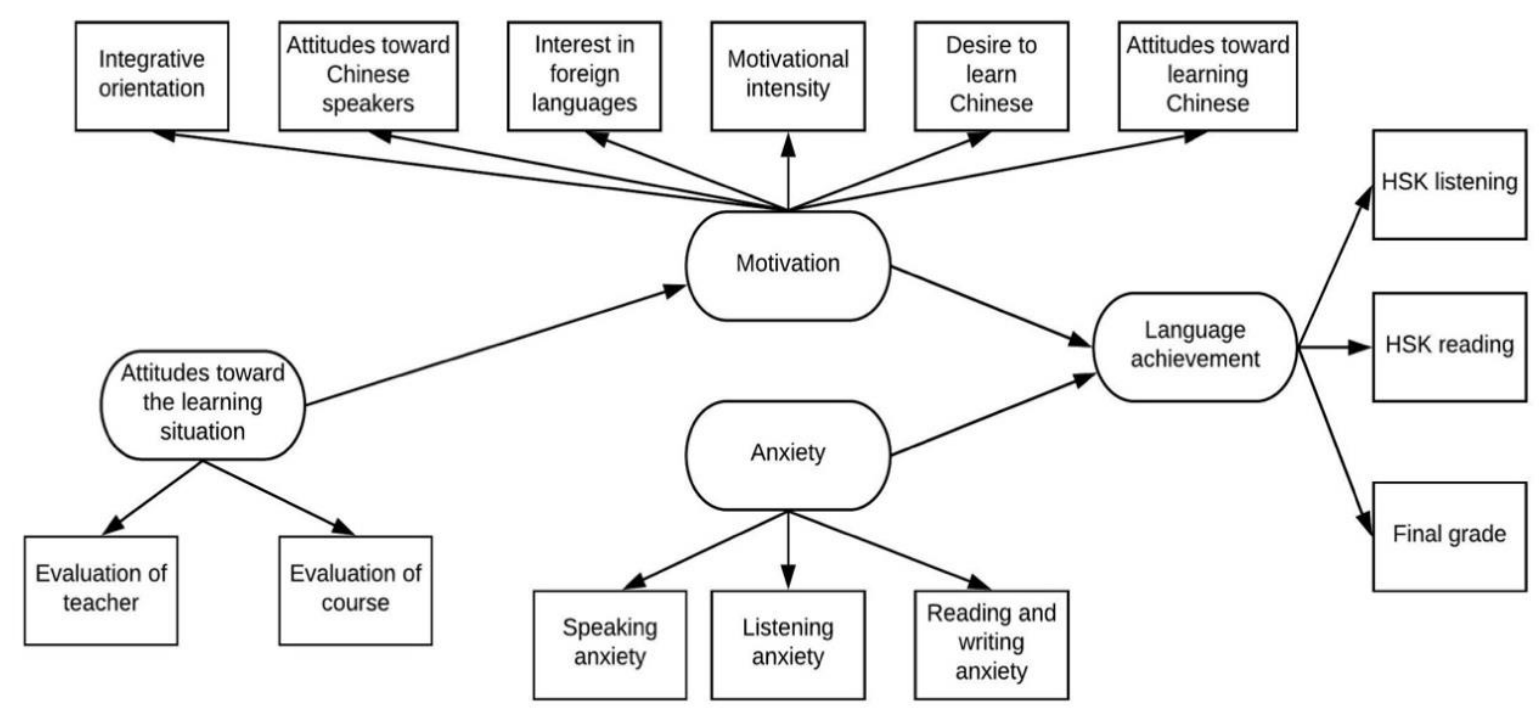

Figure 1. A schematic representation of original model

The various goodness-of-fit indexes suggested an adequate but not good fit of the proposed model. The CFI was .92, the RMSEA was .07, and the SRMR was .07. As such, the CFI and the RMSEA did not meet the criteria for a good fit. An inspection of the modification indices in the LISREL output file suggested that the motivational intensity variable was problematic, as its correlations with several other variables were not adequately accounted for in the proposed model. Therefore, a second model without the motivation intensity variable was tested (see Figure 2). This model fits the data well, and all fit indices met their respective criterion (see Table 6).

Table 6. Fit Indices for the Structural Models

\begin{tabular}{lcc}
\hline \multicolumn{1}{c}{ Index } & Original Model & Revised Model \\
\hline Chi-square & 160.60 & 105.40 \\
Degrees of freedom & 73 & 61 \\
Probability level & .00 & .00 \\
Comparative fit index (CFI) & .92 & .96 \\
Root mean square error of approximation (RMSEA) & .07 & .06 \\
Standardized root mean square residual (SRMR) & .07 & .06 \\
\hline
\end{tabular}




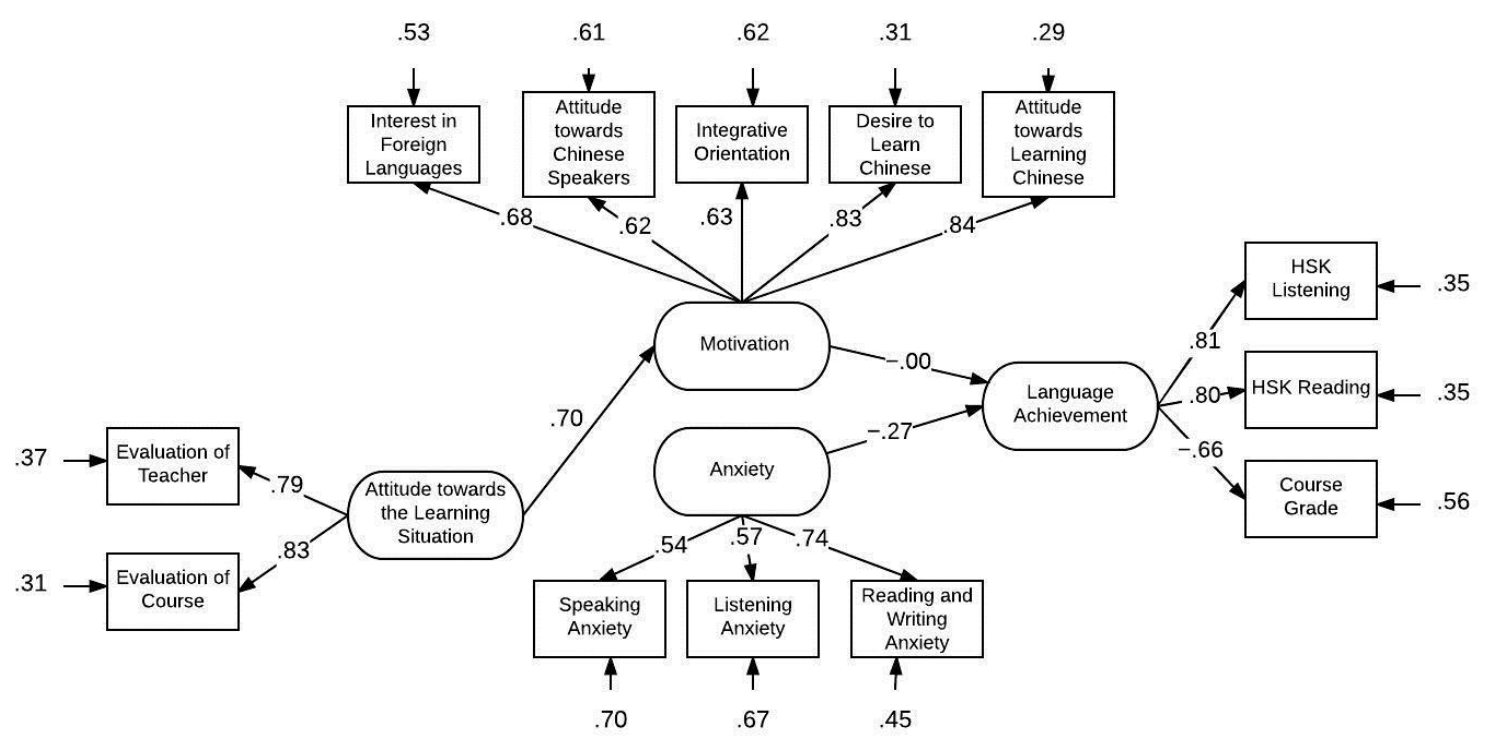

Figure 2. Standardized coefficients for revised model

Table 7 shows the predictive relationship of anxiety, motivation, attitudes toward the learning situation, and Chinese achievement. Anxiety negatively predicted Chinese achievement, $\beta=-.27, p<.05$; for every standard deviation increase in students' language learning anxiety, there was a .27 standard deviation decrease in their language achievement, other things being equal. Cohen's $f^{2}$ was used as a measure of effect size. An $f^{2}$ of .02 represents a small effect, .15 a medium effect, and .35 a large effect (Cohen, West, \& Aiken, 2003). The finding suggested a small negative effect of anxiety $\left(f^{2}=.08\right)$ on achievement. The finding also suggested that attitudes toward the learning situation positively predicted motivation; $\beta=.70, p<.01, R^{2}=.48$. For each standard deviation increase in the students' attitudes toward the learning situation, motivation increased by .70 of a standard deviation. There was a large effect $\left(f^{2}=.92\right)$ of attitudes toward the learning situation on motivation. Finally, motivation did not predict language achievement, $\mathrm{p}>.05$.

Table 7. Standardized Path Coefficients for the Revised Structural Model

\begin{tabular}{lcccc}
\hline Path & $\boldsymbol{\beta}$ & $\boldsymbol{S E}$ & $\boldsymbol{t}$ & $\boldsymbol{p}$ \\
\hline Attitude to motivation & .70 & .03 & 7.06 & .00 \\
Anxiety to achievement & -.27 & .04 & -2.68 & .01 \\
Motivation to achievement & -.00 & .27 & -.02 & .98 \\
\hline
\end{tabular}

Note: The error rate is controlled at the .05 level 


\section{Discussion and conclusion}

This study found a moderate level of anxiety for international students who were learning Chinese as a foreign language. This finding is consistent with previous research that reported moderate anxiety in the learning of English, Spanish, French, and Chinese (Horwitz, 1986; Liu \& Jackson, 2008; Luo, 2018; Rastegar \& Karami, 2015; Sellers, 2000; Subekti, 2018; Yu \& Watkins, 2008; Zhao \& Whitchurch, 2011). The only exception is the study by Le (2004) which investigated American students of Chinese at seven universities in China. The mean item score for the anxiety measure was 3.34 (out of 5), higher than the scores reported in most of the studies on second language anxiety. It is worth noting that Le's (2004) study had a homogenous sample of American students who studied in study-abroad programs in China. Compared to international students who are mostly from Asian countries, this group may experience more stress in learning due to the unfamiliar social and cultural environment. Tian and Lowe (2014), for example, studied the intercultural experience of American students in a Chinese university. They found that American students, at an early stage of their program, reported encountering a classroom culture that is quite different from what they experienced back at home. For instance, the language courses in China are usually more intensive (about four hours every day) than those in America (about four hours every week); no syllabus is provided in Chinese universities, making it more difficult for American students to follow the teacher; moreover, Chinese universities generally adopt the paper-based exams to assess students learning rather than the projects and presentations commonly used in American universities (Tian \& Lower, 2013). All these differences may be frustrating and ego threatening for American students, rendering more anxiety in language learning.

Secondly, this study tested a measurement model of motivation, integrativeness, anxiety, attitudes toward the learning situation, and Chinese language achievement. An examination of the measurement model revealed a four-factor structure instead of the five-factor structure proposed in Gardner's socio-educational model of second language acquisition (Gardner, 2006, 2010). In the four-factor structure, integrativeness and motivation are under one single construct. This discrepancy in findings may be attributed to the difference in student population being investigated. Gardner's early studies focused on learners in domestic language programs (e.g. a French-speaking region in Canada), whereas the current study examined learners in a study abroad program. In situations where students have strong interest in integrating into the target culture, such as in study abroad programs, it is possible that the learners' integra- 
tiveness and motivation cannot be easily separated. Because students have already chosen to study in the target language country, their motivation to learn the language may also be the motivation to integrate into the target culture. In fact, in a series of recent studies by Gardner in six European countries on learners of English as a foreign language (Gardner, 2006, 2010), motivation and integrativeness were found to indicate one single construct. This construct represents part of the "integrative motive" of the language learner.

Furthermore, the results of structural equation modeling in the current study revealed that anxiety had a direct and negative effect on Chinese achievement (although with a small effect size). This finding is consistent with previous findings on the negative effects of anxiety in language learning (Horwitz, Horwitz, \& Cope, 1986; Kim, 2000; Trang, et al., 2013). In addition, this study found a large effect of attitudes toward the learning situation on students' motivation to learn. The current finding provides support for Gardner's $(2006,2010)$ socioeducational model which conceptualizes anxiety as an independent influence on language achievement, and postulates that attitudes toward the learning situation directly influence learners' motivation in language learning. With the help of structural equation modeling, this study found that anxiety negatively influenced Chinese achievement when it was measured by both course grades and proficiency test scores and when other important affective variables, such as motivation, integrativeness, and attitude, were included in the model.

The fact that this study found no statistically significant effect of motivation on Chinese achievement seems to contradict the findings of Gardner and Bernaus (2010). On closer examination, however, the studies by Gardner and associates used course grades and scores on achievement tests whereas the present study used mainly proficiency tests. Achievement tests are designed to measure how much students have accomplished with respect to the learning objectives in a language course, but proficiency tests are to measure students' overall abilities in the target language (O'Sullivan \& Stoynoff, 2012). The difference in the selection of achievement measures may have led to the different findings in the current study.

To further explore this issue, three multiple regressions were conducted, each regressing one achievement measure (i.e., course grade, HSK listening, HSK reading) onto the motivation and anxiety composites. The results of the follow-up analyses showed that motivation predicted course grade $(\beta=.13, \mathrm{p}<.05)$ but not HSK test scores. This finding supports the speculation that the effects of motivation differ in proficiency tests and achievement tests. An 
achievement test is an evaluation of what has been learned in class as well as teachers' value judgment of the students' efforts. Motivated students are likely to demonstrate engagement in learning and to invest more effort in homework and test preparation, thus leading to higher test grades. In contrast, proficiency test, although assessing the students' linguistic knowledge (e.g., vocabulary and grammar), are not designed for any specific language curriculum, therefore may not be directly influenced by motivation.

To conclude, the study found a moderate level of anxiety for international students learning Chinese as a foreign language. This finding is consistent with previous studies on learners of French, Spanish, and English. It seems that second language anxiety is a universal phenomenon across different languages; Chinese is not more anxiety-inducing than other languages even though it is considered more difficult to learn for learners whose first langauge belongs to a distant linguistic group (Foreign Language Service, 2020). The results of structural equational modeling generally confirmed Gardner's $(1985,2006)$ socio-educational model of second-language acquisition. On one hand, consistent with previous literature on second language anxiety, this study found a small negative effect of anxiety on achievement and a strong positive effect of attitudes toward the learning situation on motivation. On the other hand, the findings of this study contradict research that found motivation to be an important predictor of language achievement. When the three achievement measures were looked at separately, however, motivation predicted students' course grades over and above the influence of anxiety. Therefore, it is probably appropriate to conclude that anxiety and motivation both contribute to the prediction of students' Chinese achievement when achievement is measured by course grade rather than proficiency tests alone.

\section{Limitations and future research}

The study has several limitations. First, because the participants of this study were from multiple language levels, some students may have had difficulty understanding the items on the Chinese survey. Measures were taken to address the possible language barrier in data collection. For example, translations of the survey were provided in six languages that represented the most commonly spoken languages among the international students. In addition, the Chinese survey was reviewed by the teachers before administration. Two teachers agreed that the survey was understandable by the elementary-level students when presented with the translations; all others considered the survey easy for their students to understand. Future research could examine each international student group, such as students from Thailand, to 
reduce the language barrier in data collection and to better understand the role of anxiety for each student group. Second, due to the lack of an adaptive test of Mandarin Chinese that assesses all proficiency levels, students had to take different HSK tests depending upon their language proficiency. That is, each student took one of the three HSK tests (HSK IV, HSK V, HSK VI) based on the teachers' evaluation of his or her proficiency levels. Although students' test scores were converted to z-scores to rule out teachers' influence, all tests cannot be assumed to be equal. Future research may consider investigating a single proficiency level or using tasks that suit all levels, such as writing an essay and conducting an oral interview.

\section{References}

Awan, R. N., Azher, M., Anwar, M. N., \& Naz, A. (2010). An investigation of foreign language classroom anxiety and its relationship with students' achievement. Journal of College Teaching and Learning, 7(11), 33-40.

Bekleyen, N. (2009). Helping teachers become better English students: Causes, effects, and coping strategies for foreign language listening anxiety. System, 37(4), 664-675. doi:10.1016/j.system.2009.09.010

Chen, I. J., \& Chang, C. C. (2009). Cognitive load theory: An empirical study of anxiety and task performance in language learning. Electronic Journal of Research in Educational Psychology, 7(2), 729-746.

Cocca, M., \& Cocca, A. (2019). Affective Variables and Motivation as Predictors of Proficiency in English as a Foreign Language. Journal on Efficiency and Responsibility in Education and Science, 12(3), 75-83.

Cohen, J., Cohen, P., West, S.G., \& Aiken, L.S. (2003). Applied multiple regression/correlation analysis for the behavioral sciences (2nd ed.). Hillsdale, NJ: Erlbaum.

O'Sullivan, B., \& Stoynoff, S. (2012). The Cambridge guide to second language assessment. Cambridge, United Kingdom: Cambridge University Press.

Dörnyei, Z. (2005). The Psychology of the Language Learner: Individual Differences in Second Language Acquisition (1st edition). Mahwah, N.J.: Routledge.

Dörnyei, Z. (2009). Individual differences: Interplay of learner characteristics and learning environment. Language Learning, 59, 230-248. https://doi.org/10.1111/j.14679922.2009.00542.x 
Qi Wang \& Fengning Du

Enders, C. K. (2001). A primer on maximum likelihood algorithms available for use with missing data. Structural Equation Modeling, 8, 128-141. doi: 10.1207/S15328007SEM0801_

Foreign Language Service (2020): Foreign Language Training. Retrieved from https://www.state.gov/foreign-language-training/

Gardner, R. C. (1985). Social psychology and second language learning: The role of attitudes and motivation. London, United Kingdom: Edward Arnold.

Gardner, R. C. (2006). The socio-educational model of second language acquisition: A research paradigm. EUROSLA Yearbook, 6, 237-260. doi:10.1075/eurosla.6.14gar

Gardner, R. C. (2010). Motivation and second language acquisition: The socio-educational model (1st ed.). New York, NY: Peter Lang Publishing Inc.

Gardner, R. C. (2012). Integrative motivation and global language (English) acquisition in Poland. Studies in Second Language Learning \& Teaching, 2(2), 215-226.

Gardner, R.C. \& Bernaus, M. (2010). Attitudes, motivation, and language anxiety in an EFL European Context. In R. C. Gardner (Ed.), Motivation and second language acquisition: The socio-educational model (pp. 137-155). New York, NY: Peter Lang.

Hernández, T. A. (2008). Integrative motivation as a predictor of achievement in the foreign language classroom. Applied Language Learning, 18(1\&2), 1-15.

Horwitz, E. K. (1986). Preliminary evidence for the reliability and validity of a for English language anxiety scale. In E. K. Horwitz \& D. J. Yong (Eds.), Language anxiety: From theory and research to classroom implications (pp. 37-39). Englewood Cliffs, NJ: Prentice Hall.

Horwitz, E. K., Horwitz, M. B., \& Cope, J. (1986). Foreign language classroom anxiety. The Modern Language Journal, 70(2), 125-132. doi:10.1111/j.1540-4781.1986.tb05256.x

Hu, L.T. \& Bentler, P.M. (1999). Cutoff criteria for fit indexes in covariance structure analysis: Conventional criteria versus new alternatives. Structural Equation Modeling: A Multidisciplinary Journal, 6, 1-55.

Keith, T. Z. (2015). Multiple regression and beyond: An introduction to multiple regression and structural equation modeling (2nd ed.). New York, NY: Routledge.

Kiany, G. R., \& Shayestefar, P. (2011). High school students' perceptions of EFL teacher control orientations and their English academic achievement. British Journal of Educational Psychology, 81(3), 491-508. doi:10.1348/000709910X522177 
Kim, J. (2000). Foreign language listening anxiety: A study of Korean students learning English (Doctoral dissertation). Retrieved from ProQuest Dissertations \& Theses Global (Order No. 3004305).

Kline, R. B. (2011). Principles and practice of structural equation modeling (3rd ed.). New York, NY: The Guilford Press.

Le, J. (2004). Affective characteristics of American students studying Chinese in China: A study of heritage and non-heritage learners' beliefs and foreign language anxiety (Doctoral dissertation). Retrieved from ProQuest Dissertation \& Theses Global (Order No. 305126060$)$.

Little, R. J. A. (1988). A test of missing completely at random for multivariate data with missing values. Journal of the American Statistical Association, 83(404), 1198-1202.

Liu, M., \& Jackson, J. (2008). An exploration of Chinese EFL learners' unwillingness to communicate and foreign language anxiety. The Modern Language Journal, 92(1), 71-86.

Luo, H. (2014). A measure of Chinese language learning anxiety: Scale development and preliminary validation. Chinese as a Second Language Research, 3(2), 147-174.

Luo, H. (2018). Predictors of foreign language anxiety: A study of college-level L2 learners of Chinese. Chinese Journal of Applied Linguistics, 41(1), 3-24.

MacIntyre, P. D., \& Gardner, R. (1994). The subtle effects of language anxiety on cognitive processing in the second language. Language Learning, 44(2), 28-305. doi:10.1111/j.1467-1770.1994.tb01103.x

MacIntyre, P. D., \& Gardner, R. C. (1989). Anxiety and second-language learning: Toward a theoretical clarification. Language Learning, 39(2), 251-275. doi:10.1111/j.14671770.1989.tb00423.x

Masgoret, A.-M., \& Gardner, R. C. (2003). Attitudes, motivation, and second language learning: A meta-analysis of studies conducted by Gardner and associates. Language Learning, 53(1), 167-210.

Ministry of Education of the People's Republic of China. (2016, April 14). 2015 National Statistics of International Students in China. Retrieved from http://www.moe.gov.cn/jyb_xwfb/gzdt_gzdt/s5987/201604/t20160414_238263.html

Nouri, A. (2015). The relationship between Iranian EFL teachers' behavior and academic achievement of high school students. Journal of Language Teaching \& Research, 6(3), 574-580. https://doi.org/10.17507/jltr.0603.13 
O'Sullivan, B., \& Stoynoff, S. (2012). The Cambridge guide to second language assessment. United Kingdom: Cambridge University Press.

Pérez Castillejo S. The role of foreign language anxiety on L2 utterance fluency during a final exam. Language Testing. 2019;36(3):327-345. doi:10.1177/0265532218777783.

Rastegar, M., \& Karami, M. (2015). On the relationship between foreign language classroom anxiety, willingness to communicate and scholastic success among Iranian EFL learners. Theory \& Practice in Language Studies, 5(11), 2387-2394. doi:10.17507/tpls.0511.25

Salehi, M., \& Marefat, F. (2014). The effects of foreign language anxiety and test anxiety on foreign language test performance. Theory and Practice in Language Studies, 4(5), 931-940. doi:10.4304/tpls.4.5.931-940

Scheffer, J. (2002). Dealing with missing data. Research Letters in the Information and Mathematical Sciences, $\quad 3, \quad 153-160 . \quad$ Retrieved from http://equinetrust.org.nz/massey/fms/Colleges/College\%20of\%20Sciences/IIMS/ RLIMS/Volume03/Dealing_with_Missing_Data.pdf

Scovel, T. (1978). The effect of affect on foreign language learning: A review of the anxiety research. Language Learning, 28(1), 129-142. doi:10.1111/j.14671770.1978.tb00309.x

Sellers, V. D. (2000). Anxiety and reading comprehension in Spanish as a foreign language. Foreign Language Annals, 33(5), 512-520. doi:10.1111/j.1944-9720.2000.tb01995.x

Shao, K., Yu, W., \& Ji, Z. (2013). An exploration of Chinese EFL students' emotional intelligence and foreign language anxiety. Modern Language Journal,97(4), 917-929. https://doi.org/10.1111/j.1540-4781.2013.12042.x

Shih, H.-J. (2019). L2 Anxiety, Self-Regulatory Strategies, Self-Efficacy, Intended Effort and Academic Achievement: A Structural Equation Modeling Approach. International Education Studies, 12(3), 24-35.

Shih, H.-J., \& Change, S. (2018). Relations among L2 Learning Motivation, Language Learning Anxiety, Self-Efficacy and Family Influence: A Structual Equation Model. English Language Teaching, 11(11), 148-160.

Sparks, R. L., Patton, J. O. N., Ganschow, L., \& Humbach, N. (2009). Long-term relationships among early first language skills, second language aptitude, second language affect, and later second language proficiency. Applied Psycholinguistics, 30(4), 725-755. 
Spielberger. C. D. (1976). The nature and measurement of anxiety. In C. D. Spielberger \& R. Diaz-Guerrero (Eds.), Cross-cultural anxiety: Vol. I (pp. 3-12). Washington, DC: Hemisphere.

Steiger, J.H. (2007), Understanding the limitations of global fit assessment in structural equation modeling. Personality and Individual Differences, 42 (5), 893-98.

Subekti, A. S. (2018). Investigating the Relationship between Foreign Language Anxiety and Oral Performance of Non-English Major University Students in Indonesia. Dinamika Ilmu, 18(1), 15-35.

Sultan, S., \& Hussain, I. (2010). Significance of instrumental and integrative motivation in second-language acquisition. Journal of Educational Research (1027-9776), 13(2), $145-152$.

Swanson, P. B. (2013). Spanish teachers' sense of humor and student performance on the national Spanish exams. Foreign Language Annals, 46(2), 146-156.

Talebinejad, M. R., \& Akhgar, F. (2015). The impact of teacher scaffolding on Iranian intermediate EFL learner's listening comprehension achievement. Theory and Practice in Language Studies, 5, 1101-1105. https://doi.org/10.17507/tpls.0505.27

Tian, M., \& Lowe, J. (2013). The role of feedback in cross-cultural learning: a case study of Chinese taught postgraduate students in a UK university. Assessment \& Evaluation in Higher Education, 38(5), 580-598.

Tian, M., \& Lowe, J. A. (2014). Intercultural identity and intercultural experiences of American students in China. Journal of Studies in International Education, 18(3), 281-297.

Trang, T. T. T., Baldauf Jr., B. B., \& Moni, K. (2013). Investigating the development of foreign language anxiety: An autobiographical approach. Journal of Multilingual and Multicultural Development, 34(7), 709-726. doi:10.1080/01434632.2013.796959

Vahdany, F., Sabouri, N. B., \& Ghafarnian, S. (2015). The relationship among EFL teachers, students' attitudes and their teaching-learning achievements in English. Theory \& Practice in Language Studies, 5(12), 2625-2630. doi:10.17507/tpls.0512.26

Woodrow, L. (2011). College English writing affect: Self-efficacy and anxiety. System, 39(4), $510-522$.

Yu, B., \& Watkins, D. A. (2008). Motivational and cultural correlates of second language acquisition: An investigation of international students in the universities of the People's Republic of China. Australian Review of Applied Linguistics, 31(2), 17.1-17.22. 
Zhang, X. (2019). Foreign Language Anxiety and Foreign Language Performance: A Meta-Analysis. Modern Language Journal, 103(4), 763-781. https://doi.org/10.1111/modl.12590

Zhao, A., \& Whitchurch, A. (2011). Anxiety and its associated factors in college-level Chinese classrooms in the US. Journal of the Chinese Language Teachers Association, $46,21-47$.

Received: $21-02-2020$

Accepted: 04-06-2020 